City University of New York (CUNY)

CUNY Academic Works

2016

\title{
Vulnerability and Exposure to Crime: Applying Risk Terrain Modeling to the Study of Assault in Chicago.
}

Leslie W. Kennedy

Rutgers University

Joel M. Caplan

Rutgers University

Eric L. Piza

CUNY John Jay College

Henri Buccine-Schraeder

Rutgers University

\section{How does access to this work benefit you? Let us know!}

More information about this work at: https://academicworks.cuny.edu/jj_pubs/180

Discover additional works at: https://academicworks.cuny.edu

This work is made publicly available by the City University of New York (CUNY).

Contact: AcademicWorks@cuny.edu 


\title{
Vulnerability and Exposure to Crime: Applying Risk Terrain Modeling to the Study of Assault in Chicago
}

\author{
Leslie W. Kennedy ${ }^{1} \cdot$ Joel M. Caplan ${ }^{1}$. \\ Eric L. Piza ${ }^{2}$ - Henri Buccine-Schraeder ${ }^{1}$
}

Received: 29 December 2014 / Accepted: 10 August 2015 /

Published online: 27 August 2015

(C) Springer Science+Business Media Dordrecht 2015

\begin{abstract}
Prior research has applied risk assessment and spatial analysis techniques to the study of violence. This paper builds on those results, tying the practical outcomes of spatial risk analysis methods to broader spatial issues on the articulation of risky places for aggravated assault. We begin by conceptualizing key relationships, addressing the effects of environmental factors on creating distinct, identifiable areas that are conducive to crime. Propositions of the theory of risky places are posed and then empirically tested using a GIS based program, RTMDx, on aggravated assault data in an urban area. Given the current thinking about crime vulnerability based on concentration and spatial influence of features and events, this paper offers an analytical strategy to model risky places that combines the conceptual insights of crime emergence and persistence, advances in geo-spatial analytical techniques, and micro-level data.
\end{abstract}

Keywords Risk terrain modeling · Spatial influence · Vulnerability · Exposure and aggravated assault . Theory of risky places

Leslie W. Kennedy

lefkennedy@gmail.com

Joel M. Caplan

nalpac@gmail.com

Eric L. Piza

epiza@jjay.cuny.edu

Henri Buccine-Schraeder

buccine@gmail.com

1 Rutgers Center on Public Security, Rutgers University School of Criminal Justice, Newark, NJ, USA

2 Department of Law and Police Science, John Jay College of Criminal Justice, New York, NY, USA 


\section{Introduction}

\section{Risky Places}

A focus on risky places for crime is not new (Mayhew 1861; Park et al. 1925; Shaw and McKay 1969; Bursik and Grasmick 1993) and the clustering of crime at specific places is well supported by contemporary research (e.g., Caplan et al. 2011; Eck et al. 2005; Harries 1999; Kennedy et al. 2011; Sherman et al. 1989; Weisburd et al. 2009). Braga and Clarke (2014) present a compelling argument for studies of micro-places that concentrate on risks associated with certain types of environmental features. These features can create opportunities for crime, attract offenders, and confound agents of social control in containing offenders' negative effects. But, at the same time, an understanding of one or more environmental features' relative importance in creating vulnerability to crime can offer geographically focused strategies for prevention and mitigation of crime exposure (see Eck et al. 2007; Guerette and Bowers 2009; Hunter and Jeffery 1997; Sherman and Rogan 1995).

Geographically focused, or place-based, policing practices have consistently demonstrated effectiveness. A recently updated meta-analysis of hotspots policing interventions (Braga et al. 2014) identified 19 studies of hotspots policing efforts with sufficiently rigorous designs, 17 of which reported noteworthy crime reductions. Placebased interventions can offer a more efficient method of policing than offender-based strategies. This presents an evidence-based change in approach for law enforcement officers who work to control criminal behavior. If they increase their effectiveness in managing locations, the likelihood is that crimes should drop. However, hotspot approaches to crime analysis do not provide clues to why the problems continue to concentrate in certain areas over long durations of time (see recent article by Koper 2014 that discuss the challenges faced in hotspots policing). They point to locations where crimes cluster over time, but do not inherently explain why at these particular places.

As an extension of, or companion to, hotspots analysis, the phenomenon of contagion has been labeled "near repeats" (Ratcliffe and Rengert 2008) and explains how recent-past crime incidents can serve as predictors of new crime incidence (Bowers and Johnson 2005). Investigations of near repeats provide an important extension of hotspot analysis as they account for the temporal link between crime events. However, crime suppression and prevention efforts at spatially and temporally high-crime places cannot fully succeed outside of an understanding of the unique physical environments in which the illegal behavior occurs (Weisburd et al. 2009).

Evidence suggests that analyzing the risk heterogeneity of a landscape along with event-dependent assessments of crime is useful for generating a more complete understanding of crime problems at specific places (e.g., Kennedy et al. 2011; Weisburd et al. 2006; Caplan et al. 2013a; Moreto et al. 2013). Brantingham and Brantingham (1981) referred to an "environmental backcloth" that emerges from the confluence of routine activities and physical structures overlaying areas. Included in this backcloth are "crime attractors" and "crime generators" that serve to concentrate crime in specific locations, or hotspots (Brantingham and Brantingham 1995). Attractors are those specific things that entice people to come to places in order to commit crime. Generators suggest that there are greater opportunities for crime that emerge from increased volume of 
interaction that happens in these locations. The Brantinghams' interest in the environmental backcloth centered on the effects that single environmental features have on crime behavior (although it is clear that these attractors and generators brought people into contact with one another in criminogenic environments). The recent work on crime places revisits this interest in environment and crime, and the innovative view of "place as case" suggests that if crime can be seen as situationally located, it is more likely to be mitigated and prevented (Lum and Koper 2013).

\section{Vulnerability and Exposure to Crime}

Assigning risk levels to certain features of the environment requires that we understand (e.g., through past research or experiences) their relative importance in attracting illegal behavior and supporting crime. The risk posed by criminogenic features is located at one or more places on a landscape and their confluence at the same place contributes to a risk value that indicates the likelihood of crime. These spatial risk values, which measure the clustering of contributing factors at specific places, represent vulnerability to crime and can be used to forecast where crime will occur and (possibly) cluster over a period of time (Caplan and Kennedy 2010; Drawve 2014; Dugato 2013; Yerxa 2013).

Affecting this forecast of crime incident locations, however, is the problem that while an area may be vulnerable to illegal behavior, crime does not always occur there. That is, a model that uses only spatial vulnerability to determine crime outcomes may suggest that the likelihood is high, but crime may not happen as predicted. This results in false positive predictions that incorrectly inform the allocation of resources to areas that could attract or encourage crime, but do not always. This is a problem in all forecasting models (see Silver 2012). But, incorporating exposure into a spatial vulnerability model helps to reduce the effects of false positives by considering the risks that past experience with crime present at vulnerable places. This increases the chances that forecasts will be true when suggesting where crime will occur. In the terms used by Silver, this study presents how we adjust our empirical place-based assessment of crime outcomes given knowledge from past experience (i.e., hotspots of crime) and environmental features of the landscape that increase the probability of illegal behavior (i.e., vulnerable places). We test this vulnerability-exposure approach to spatial risk assessment for crime in the analysis that follows.

Some places, we know, are more likely to be locations of crime than others; that is, where "exposure" to crime events is relatively high. This may be the case because of the characteristics of people who frequent these places or it may have something to do with the qualities of the environments themselves. If we concentrate on the characteristics of people, we can focus on their propensity to offend or, for victims, their susceptibility to offending. If we concentrate on the characteristics of places, we can focus on the factors that are conducive to crime occurrence, offering a means by which to target certain places that are more likely to promote illegal behavior. Both approaches have merit and have helped researchers create a more complete picture of the underlying processes that contribute to crime. The task of the criminologist is not simply to explain what is happening but also to provide prescriptions for how to use knowledge to combat crime and its consequences.

Cartographically modeling vulnerability as the clustering of criminogenic features of a landscape, and then interpreting vulnerability in the context of exposure, permits a 
research strategy to identify, monitor and control these environments. But, establishing the connection between criminogenic features and crime depends on one's ability to operationalize spatial influence emanating from such features to all places throughout the landscape (Caplan 2011).

This study explores how place-based exposures to (i.e. recent past incidences of) aggravated assault are established on existing spatial influences of the environmental backcloth and, therefore, increase the risk of future illegal behavior and crime at certain micro-level locations. In looking at this, we apply a spatial analysis technique that considers the relative importance of multiple features of a landscape in influencing illegal behavior and crime occurrences. The usefulness of this vulnerability-exposure framework for police agencies in devising implementation strategies to mitigate and prevent crime will also be discussed.

\section{Spatial Influence}

Spatial influence describes the way in which features of a landscape affect places throughout the landscape (Caplan 2011). Studies of spatial influence are not found solely in criminological studies. For example, spatial influence has been used in geographical studies and for the study of health and disease related issues (Lawson et al. 1999; Lim et al. 2013). The thinking behind spatial influence is based on Tobler's first law of geography: "Everything is related to everything else, but near things are more related than distant things" (Tobler 1970). If this is true (both in terms of promoting or discouraging certain types of behavior), then the cumulative effects should be such that certain places within the spatial influence of many criminogenic features would be more vulnerable to crime than places that are not influenced by one or more criminogenic features. Operationalizing the spatial influence of crime risk factors addresses various theoretical and methodological issues concerning the use of GIS for assessing place-based crime or victimization risk (Freundschuh and Egenhofer 1997). Most basically, it maximizes the validity of cartographic models and empirical measures used for statistical tests (Golledge and Stimson 1997; Caplan 2011; Freundschuh and Egenhofer 1997).

Spatial influence involves consideration of the attractive qualities (Brantingham and Brantingham 1995) of single features or feature sets, such as bars, clubs or dance halls, on locations of crimes. The influence that radiates beyond the physical feature itself is assumed in the idea that certain areas attract illegal behavior, not because crime always takes place there, but because of the features of the environment that are conducive to crime occurrence. And, this is true not always at the exact location of these features' physical addresses, but within certain proximities to them (Taylor and Harrell 1996). Spatial influence can also take into account the fact that a particular risk factor has a particularly strong and lasting impact on crime. That is, high-crime areas tend to be resilient over time, even if individual offenders are arrested and physically removed from the location. Unless actions are taken to mitigate the spatial influences of factors that attract offenders to the same area over and over again, tomorrow's crime incidents are likely to continue to occur at yesterday's high-crime areas. We can think of such things as "problem" bars or drug markets that police or other agencies have identified as having a great likelihood of causing hazards and, therefore, warranting special 
attention. If we think about adding these problem areas into our analysis, we can consider supra-spatial meaning attached to certain types of facilities.

\section{Research Propositions for the Study of Crime Using the Vulnerability-Exposure Framework}

This study addresses which factors relate to crime outcomes; considers the importance of risk factors relative to one another and weights them; suggests how these factors, when they overlap, create vulnerable (i.e., risky) places; and then isolates the catalyzing effect of crime events on new crime incidents at vulnerable places (Kennedy and Caplan 2013). The three key propositions of the theory of risky places are as follows:

1) All places are at risk for crime, but because of the spatial influence of certain criminogenic features of a landscape, some places are riskier than others;

This proposition addresses the direct spatial influence (Tobler 1970) that risk factors, as studied in previous literature, have on assaultive behavior. This current study advances what has been done previously as we look at the relative importance of these factors when considered together, rather than single effects. We can add to this consideration of risk a suggestion that certain types of facilities, known to be stronger attractors of crime, will be where we will find the most crime.

2) Crime emerges at places when there is high vulnerability based on the combined spatial influences of multiple criminogenic features at said places;

Vulnerability comes from the emergence of settings that, because of the presence of a combination of risk factors' spatial influences, enhance the likelihood of illegal behavior. The resulting spatial inference acquired from this analysis addresses interactions that occur among risk factors to support aggravated assault behavior and ultimately crime incidence, which can be mapped and used as reference points for intervention and crime suppression activities.

3) The overall effect of risky places on crime is a function of differential vulnerability and exposure throughout the landscape.

We can say that a place is vulnerable based on the co-location of criminogenic features, but this is not solely important if there are no recent nearby exposures to crime. But, if crime occurred at the place before and if the place is spatially vulnerable, then the likelihood that crime will occur in the future increases. This framework operationalizes the vulnerability-exposure analytical approach that looks at the joint utility of hotspots, environmental risks, and near repeats (Caplan et al. 2013a). We can characterize insights from the vulnerability-exposure analysis as spatial intelligence, suggesting that differential effects of vulnerability in the context of exposure provide actionable evidence for place-based policing efforts.

For the purposes of testing these propositions, we study aggravated assault in Chicago, IL. We will identify the environmental factors for this crime type and apply a series of tests to demonstrate how the vulnerability-exposure framework can be 
operationalized consistent with the assumptions about crime concentration and the literature reviewed above.

\section{Studying Assault}

Despite its pervasiveness and harmful effects, aggravated assault has not been extensively explored. Studies show that it occurs frequently where drugs or alcohol are present. Reports from victimization studies show that as many as $33.5 \%$ of offenders arrested for aggravated assault were perceived to be under the influence of drugs or alcohol (Rand 2008). Research has demonstrated that there is a significant association between the density of assaults and alcohol outlets (Scott and Dedel 2006; Pridemore and Grubesic 2013). Furthermore, there is a positive correlation between the total alcohol outlet density (e.g., bars, liquor stores, etc.) and the number of aggravated assaults (Snowden and Pridemore 2013). On the contrary, however, some research has found that the density of bars is not necessarily positively correlated with aggravated assault incidents (Pridemore and Grubesic 2013). This may be partially explained by distinction between on-premise and off-premise alcohol outlets. An on-premise alcohol outlet is one where alcohol is served and consumed in the same location, whereas an off-premise alcohol outlet is one where alcohol is sold for convenience. The packageonly alcohol outlets' density (i.e., off-premise) may be more likely to increase violent crimes like aggravated assault whereas the density of bars (i.e., on-premise) has shown no effect on violent crime rate (Snowden and Pridemore 2013).

Aggravated assault is also reported to occur at sporting venues, shopping malls, and concert halls where there is alcohol and adversarial encounters between spectators (Madensen and Eck 2008). This conforms to the idea that in places where there are attractors and generators of crime, interpersonal violence will be higher.

The location of drug markets and gang territories have been tied to assault (U.S. Department of Justice, National Gang Intelligence Center 2009; Braga et al. 2008). Violence is often a central part of the drug trade where disputed transactions are resolved through violence or conflicts develop around turf (Office of National Drug Control Policy 2000). Drug activity, in general, has shown to be positively correlated with higher rates of all violent crime, specifically aggravated assault, when levels of social disorganization are held constant (Martinez et al. 2008).

Knowing that aggravated assault is likely to occur near certain features of a landscape, the question that is raised relates to the relative importance of these risky features, when combined, in creating places for assaultive behavior and these crime incidents to occur. Next, we can focus attention on certain features of the Chicago landscape. We apply the vulnerability-exposure framework to study spatial patterns of assaults in ways that are insightful for developing strategies to mitigate the effects of risky places on the emergence of crime events using geo-spatial technologies that test for spatial influence.

\section{Study Setting and Data Sources}

Chicago is one of the major cities in the United States and the largest city in Illinois, with a long history of serious crime problems. In 2012 Chicago suffered a spike in 
homicides and gun violent incidents. The dramatic jump to 500 homicides in the city a $16 \%$ increase compared to 2011 - prompted city officials to rethink policing strategies. Lax gun laws in jurisdictions outside of the city border, feuding gangs and delinquent groups, drugs, and dispersed clusters of poverty seemed to have fueled violence in Chicago. Although Chicago now appears to be following a trend of decreasing rates of aggravated assaults (as similarly experienced across the country), the rates seem to be approximately double that of the rest of the US between 2005 and 2008, and approximately $150 \%$ higher between 2010 and 2012. Violent crime is an ongoing problem in the city. Aggravated assault covers a wide range of criminal behaviors, from shootings to beatings in which victims sustain serious injuries. In Chicago, aggravated assault is defined as an illegal attack by a person where the offender displays a weapon in a manner that is threatening (Chicago Police Department). In Chicago there were over 12,000 aggravated assaults in 2012, giving us a large number of incidents to examine across the large expanse of the city. Aggravated assault also offers the chance to test the contextual effects of place on "street" crime.

\section{Environmental Risk Factors}

Environmental risk factors for this study were selected based on the empirical research evidence and the knowledge of personnel at the Chicago Police Department, who provided practical experience-based justification for the use of some factors. As a consequence, the factors included in this study are not only empirically driven but are also practically meaningful. Initially, there were 23 risk factors (discussed below) identified for inclusion in the study. Data on business infrastructure were obtained from InfoGroup, a leading commercial provider of public record information for reference, research, and marketing purposes. Other data, including point-level crime data for calendar years 2011 and 2012, were obtained from the Chicago Police Department (CPD). Calls for service (311) data were obtained from the City of Chicago's Data Portal (https://data.cityofchicago.org). The Data Portal is a compilation of datasets provided by Chicago city agencies in the interest of public accessibility (City of Chicago 2014).

Some of the potential risk factors mirror those used in previous studies of land use features, including apartment complexes, automatic teller machines (ATMs), gas stations, gas stations with convenience stores, ${ }^{1}$ grocery stores, healthcare centers and gymnasiums, homeless shelters, laundromats, post offices, retail shops, schools, bus stops and variety stores (Kennedy et al. 2011; Kennedy and Van Brunschot 2009; Bernasco and Block 2011; Irvin-Erickson 2015; Weisburd et al. 2012; Stucky and Ottensmann 2009; Groff and La Vigne 2002). We added land use features that were recommended by Chicago police officers and are based on composite measures of risk: problem buildings and gang hotspots. These are socially derived characteristics that identify locations in ways that go beyond their basic physical makeup. These variables were constructed by the Chicago Police Department (CPD) based on information provided by other city departments and intelligence agencies within the CPD. This is consistent with the use of composite variables that were created by the Newark police

\footnotetext{
${ }^{1}$ The layers were not mutually exclusive. However, spatial influence of the convenience store gas stations may be different from the overall dataset, so it made sense to test them on their own.
} 
department related to gang locations described by Kennedy et al. (2011). These added variables derive from an ad-hoc approach that is consistent with police intelligence practices and integrates these data appropriately into the more evidence-based approaches that derive from past research.

A separate set of variables that addressed social disorder were measured through foreclosures, 311 service requests about abandoned vehicles and 311 service requests about street lights all out. These factors reflect the use of newly available open data on land use that comes from agencies outside of the police department. Using these variables allows us to tap into the factors that have been discussed in the literature on "broken windows" and the direct impact that physical decline has on crime.

Finally, environmental factors that could be considered crime attractors included entertainment areas represented by recreation centers and rental halls, bars (on-premises), liquor stores (off-premises), and nightclubs (Scott and Dedel 2006; Block and Block 1995; Madensen and Eck 2008; Maguire 2007; Hunter and Jeffery 1997; Roncek and Faggiani 1985; Rengert et al. 2005).

It might be suggested that the use of variables specific to Chicago could compromise generalizability. So, we expressly point out research by Barnum et al. (2013) to highlight that standard patterns of crime should not be expected across study settings. Think about this through the analogy of a kaleidoscope that represents the particular environment, or setting, that we are interested in studying. The shards of different colors represent features of that environment, such as bars, fast food restaurants, grocery stores, etc. that may attract illegal behavior and create spatial vulnerabilities. Just as we see different patterns emerge when the kaleidoscope is turned, these factors combine in unique spatial and situational contexts that have implications for behavior at those places as we move from jurisdiction to jurisdiction. Mindful of the kaleidoscope metaphor, the methodology proposed here for studying crime patterns can be used to achieve consistency of analyses across various jurisdictions (with local datasets, as appropriate). Behavior settings differ, so it's not unreasonable that datasets need to be tailored accordingly. The vulnerability-exposure framework discussed below can be applied elsewhere to produce information products that provide direct decision-support for stakeholders in the unique study setting.

\section{Methods and Analysis}

\section{Spatial Influences of Aggravated Assault Risk Factors: Testing Proposition 1}

There are several ways to make sense of the forces that affect the spatial influence of criminogenic features and, ultimately, create risky places for aggravated assaults. Understanding spatial influence includes evaluating the effects of distance or density of criminogenic features on crime occurrence and assessing the importance of each feature relative to one another (Caplan 2011). Once the spatial influences of criminogenic features are understood, they must be cartographically modeled, meaning they must be operationalized to a map of the study area.

The challenge is to produce a realistic depiction of how risk posed by each feature distributes itself over space. Here, Chicago was modeled as a continuous surface GRID of $426 \mathrm{ft}-$ by- $426 \mathrm{ft}$ cells $(N=36,473)$, each representing a micro-level place throughout 
the city. This spatial dimension has practical meaning, since the cell size corresponds to the average block face of Chicago's street network and is likely the most realistic unit police can be deployed to at the micro level.

Empirical research by Taylor and Harrell (1996) suggests that crime-prone places typically comprise just a few street blocks, which qualify as behavior settings that are "regularly occurring, temporally and spatially bounded person-environment units" (Taylor 1988). To identify the optimal spatial influence of criminogenic features within a few street blocks in Chicago, we operationalized multiple variables from the previously mentioned 23 potential criminogenic features, or "risk factors." These variables were defined by one of three spatial influential distances up to three blocks: For each of the 23 risk factors' feature points in a GIS, we measured whether each raster cell in the GRID was within 426,852 , or $1278 \mathrm{ft}$ of the feature points or in an area of high density of the feature points based on a kernel density bandwidth of 426, 852, or $1278 \mathrm{ft}$ feet. This resulted in as many as six variables ${ }^{2}$ of spatial influence measured as a function of Euclidean distance or kernel density at up to 1, 2, or 3 blocks (thresholds) from each risk factor, respectively. This process generated 111 variables $^{3}$ that were tested for significance with locations of aggravated assault incidents in Chicago. Raster cells within the study extent that were inside each threshold Euclidean distance were represented as 1 (highest risk); cells outside this distance were represented as 0 (not highest risk). Density variables were recoded using a dichotomous scale, with all variables at or greater than two standard deviations above the mean classified as 1 (highest risk) and all others being classified as 0 (not highest risk). All of these values were assembled into a table where rows represented cells within the Chicago study area GRID and columns represented binary values (i.e., 1 or 0 , as just described above). Counts of calendar year 2011 aggravated assault incidents (the dependent variable) located within each raster cell were also recorded.

In conducting the analysis, we used the RTMDx Utility, developed by the Rutgers Center on Public Security (Caplan et al. 2013b). The Utility applies a precise set of statistical tests, to be explained in the following discussion, in evaluating the relative importance of risk factors in influencing crime outcomes. To test Proposition 1, using the RTMDx Utility, the procedure began by building an elastic net penalized regression model assuming a Poisson distribution of events. This analysis used R, an open-source statistical software package (www.r-project.org), with the following code (Heffner 2013):

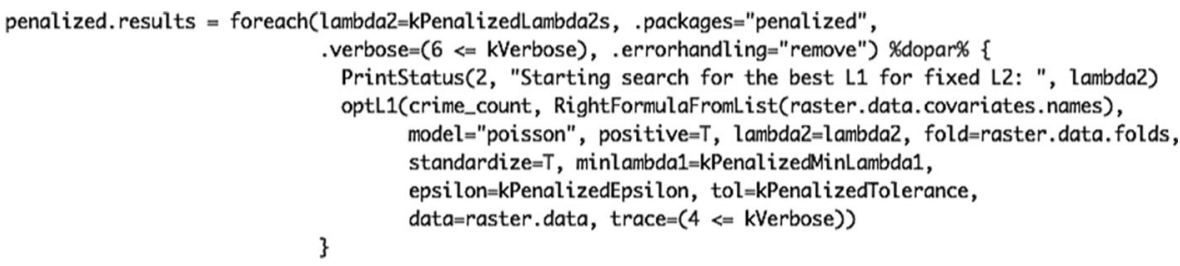

\footnotetext{
${ }^{2} 14$ potential risk factors were tested for spatial influences of both distance and/or density, up to three blocks, whole increments. Nine potential risk factors were tested for spatial influences only as a function of distance. [See page 28 of Caplan et al. (2013b) for a detailed explanation as to why these parameters were chosen.] ${ }^{3}$ (14 factors $* 2$ operationalizations $* 3$ blocks $)+(9$ factors $* 1$ operationalization $* 3$ blocks $)=111$ variables.
} 
Generating 111 variables presents potential problems with multiple comparisons, in that, we may uncover spurious correlations simply due to the number of variables tested. To address this issue, the Utility uses cross-validation to build a penalized Poisson regression model using the 'penalized' $\mathrm{R}$ package. Penalized regression balances model fit with complexity by pushing variable coefficients towards zero. The optimal amount of coefficient penalization was selected via cross-validation, which bypasses the use of statistical significance tests to select variables. This process reduces the large set of variables to a smaller set of variables with non-zero coefficients. It is important to note that using the model resulting from this step, i.e., the penalized model, would be perfectly valid in-and-of-itself (Heffner 2013). All resulting variables from this process play a useful ("significant") part within the model. But, since the goal is to build an easy to understand representation of crime risk, the Utility further simplifies the model in subsequent steps (via a bidirectional step-wise regression process).

Through cross validation (Arlot and Celisse 2010), 62 variables were selected as potentially meaningful. These variables were then utilized in a bidirectional step-wise regression process starting with a null model to build an optimal model by optimizing the Bayesian Information Criteria (BIC). The BIC score balances how well the model fits the data against the complexity of the model. Simply put, the lower the BIC score, the better the model fit. This analyses was performed in $\mathrm{R}$ using the following code (Heffner 2013):

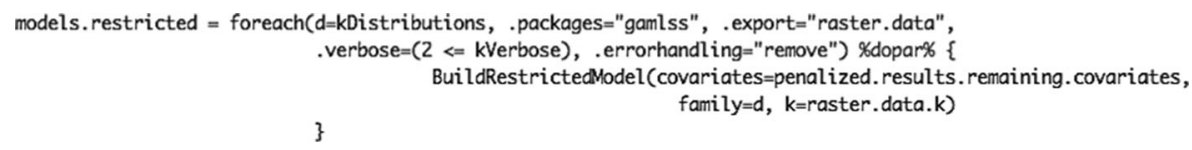

The RTMDx Utility used the "gamlss" R package to conduct a bidirectional stepwise regression. In this custom regression, the BIC scores were used to select the best model from the "pool" of 62 possible risk factor variables. To find the best model, the Utility started with a null model with no model factors, and measured the BIC score for the null model. Then, it added each model factor to the null model, and re-measured the BIC score. Every time the BIC score was calculated, the model with the best (lowest) BIC score was selected as the new candidate model (the model to surpass). The Utility repeated the process adding and removing variables one step at a time until no factor addition/removal surpassed the previous BIC score. The Utility repeated this process with two stepwise regression models: one model assumed a Poisson distribution and the other one assumed a negative binomial distribution. At the end, the Utility chose the best model with the lowest BIC score between Poisson and negative binomial distributions. The Utility also produced a relative risk value (RRV) for each risk factor, which allows for the comparison of criminogenic effect across the risk factors. These RRVs can be interpreted as the weights of risk factors. RRVs were produced through exponentiation of the coefficient values for each risk factor (Heffner 2013). For a more detailed explanation of the statistical procedures see the RTMDx Utility User Manual (Caplan et al. 2013b).

Thirteen risk factors were found to have significant spatial associations with aggravated assault incidents according to their spatial influence. In order of their relative risk 
values, the factors are: problem buildings, gang hotspots (i.e., known gang territories), foreclosures, bus stops, liquor stores, bars, grocery stores, gas stations, schools, 311 service requests for street lights all out, apartment complexes, 311 service requests about abandoned vehicles, and variety stores. The most meaningful operationalizations and spatial influential distances of each risk factor are presented in Table 1. The relative risk values can be easily compared. For instance, a place influenced by problem buildings has an expected rate of crime that is twice as high than a place influenced by grocery stores (RRVs: 2.84 / 1.42=2). Accordingly, as posited in Proposition 1, all places may have some risk of crime occurrence, but because of the spatial influence of certain criminogenic features, some places are riskier than others. In particular, we find that problem buildings, drug hotspots and foreclosures have the strongest influence on locations for aggravated assault.

\section{Spatial Influence in the Modeling of Vulnerability: Testing Proposition 2}

Now we consider the role that the combination of spatial influences of criminogenic features has on crime occurrence. Caplan et al. (2011) and Kennedy et al. (2011) measured the place-based interaction of several criminogenic features using risk terrain modeling, or RTM. RTM is an approach to risk analysis whereby separate map layers representing the spatial influences of criminogenic features are created in a geographic information system (GIS). Then all risk map layers are combined to produce a composite "risk terrain" map with values that account for the spatial influences of all features at every place throughout the landscape. Specifically within the context of RTM, modeling refers to the process of attributing qualities of the real world to places throughout a landscape, and combining multiple landscapes together to produce a single composite map where the newly derived value of each place represents the compounded criminogenic risk (i.e., vulnerability) of that place. RTM offers a

Table 1 Risk factors, spatial influence, and relative risk values of the risk terrain model

\begin{tabular}{llll}
\hline Risk factor & Spatial influence (Operationalization) & Coefficient & Relative risk value \\
\hline Problem buildings & $426 \mathrm{ft}$ (Proximity) & 1.0458 & 2.84 \\
Gang hotspots & $852 \mathrm{ft}$ (Proximity) & 0.92848 & 2.53 \\
Foreclosures & $852 \mathrm{ft}$ (Proximity) & 0.92104 & 2.51 \\
Bus stops & $426 \mathrm{ft}$ (Density) & 0.57046 & 1.76 \\
Liquor stores & $426 \mathrm{ft}$ (Density) & 0.52086 & 1.68 \\
Bars & $426 \mathrm{ft}$ (Density) & 0.41855 & 1.51 \\
Grocery stores & $852 \mathrm{ft}$ (Density) & 0.35358 & 1.42 \\
Gas stations & $1278 \mathrm{ft}$ (Proximity) & 0.25476 & 1.29 \\
Schools & $1278 \mathrm{ft}$ (Proximity) & 0.23762 & 1.26 \\
311 requests for all street lights out & $852 \mathrm{ft}$ (Proximity) & 0.22555 & 1.25 \\
Apartment complexes & $1278 \mathrm{ft}$ (Proximity) & 0.16805 & 1.18 \\
311 requests for abandoned vehicles & $1278 \mathrm{ft}$ (Proximity) & 0.16764 & 1.18 \\
Variety stores & $1278 \mathrm{ft}$ (Proximity) & 0.1504 & 1.16 \\
Intercept & - & -4.1625 & - \\
\hline
\end{tabular}


statistically valid way to articulate vulnerable areas at the micro-level according to the spatial influence of many criminogenic features. Spatial vulnerability, as measured by composite risk values in a risk terrain model, does not create crime. It simply appraises locations where, if the conditions are right, the risk of crime or victimization will be high.

The second proposition, "crime emerges at places when there is high vulnerability based on the combined spatial influences of criminogenic features," can be tested with a risk terrain model for aggravated assaults in Chicago. Places in Chicago with higher risk values should have greater expected aggravated assault counts than places with low risk values. According to the statistical procedure described above, the RTMDx Utility determined that the best risk terrain model was a Negative Binomial type II model with 13 risk factors and a BIC score of 33,364.

Risk map layers of the 13 risk factors included in the model were combined through map algebra (Tomlin 1994) using ArcGIS for Desktop's Raster Calculator, to produce a risk terrain map. Referring to Table 1, the risk terrain map was produced using the following formula:

$$
\begin{aligned}
& \operatorname{Exp}(-4.1625+1.0458 * \text { * ProblemBuildings" }+0.92848 * \text { "Gang Hotspots " }+0.9 \\
& 2104 * \text { " Foreclosures" }+0.57046 * \text { " Bus Stops" }+0.52086 * \text { "Liquor Stores" }+0 \\
& .41855 * \text { "Bars" }+0.35358 * \text { "Grocery Stores" }+0.25476 * \text { "Gas Stations" }+0.23 \\
& 762 * \text { "Schools" }+0.22555 * \text { "311 Service Requests for All Street Lights Out" }+0 \\
& .16805 * \text { "Apartment Complexes" + } 0.16764 * \text { "311 Service Requests for Abando } \\
& \text { n e d Vehicles " }+0.1504 * \text { "Variety Stores ") / E x p (-4.1625) }
\end{aligned}
$$

As shown in Fig. 1, relative risk values ${ }^{4}$ for each cell in the risk terrain map ranged from 1 for the lowest risk cell to 334.4 for the highest risk cell. A cell with a value of 334.4 has an expected rate of crime that is 334.4 times higher than a cell with a value of 1. The mean risk value is 13.8 , with a standard deviation of 18.96 .

Proposition 2 posits that new crime incidents are likely to emerge at places when there is a high vulnerability based on the combined spatial influences of multiple criminogenic features at said places. So, the risk terrain map of Chicago was added to ArcMap where counts of calendar year 2012 aggravated assault incidents were joined to each $426 \mathrm{ft}$ GRID cell. Presumably, this risk terrain map created and validated on the spatial patterns of aggravated assaults during calendar year 2011 would be a statistically significant "predictor" of 2012 aggravated assault incident locations.

Proposition 2 was tested through a negative binomial regression model with the count of 2012 aggravated assaults as the dependent variable and a cell's Risk Value as the independent variable. ${ }^{5}$ In addition, a spatial lag variable was included as an independent variable in order to control for the observed presence of spatial autocorrelation. ${ }^{6}$ As shown in Table 2, the Incidence-Rate Ratio (IRR) from a negative binomial regression suggests that the aggravated assault count increases $2 \%$ (IRR= 1.02) for every unit increase of risk at a $426 \mathrm{ft}$ cell. The mean and standard deviation of

\footnotetext{
${ }^{4}$ Created by rescaling the grid cell values between the minimum and maximum values.

${ }^{5}$ Results from a Poisson goodness-of-fit test confirmed that the 2012 aggravated assault incident locations (the dependent variable) follow a negative binomial distribution (Pearson gof $=53187.49, p<0.001$ ).

${ }^{6}$ Moran's I was 0.24 and was significant at $p<0.001$. The Moran's I analysis was conducted within the Geoda spatial analysis software. Geoda was also used to generate the spatial lag variable (first order Queen Continuity).
} 


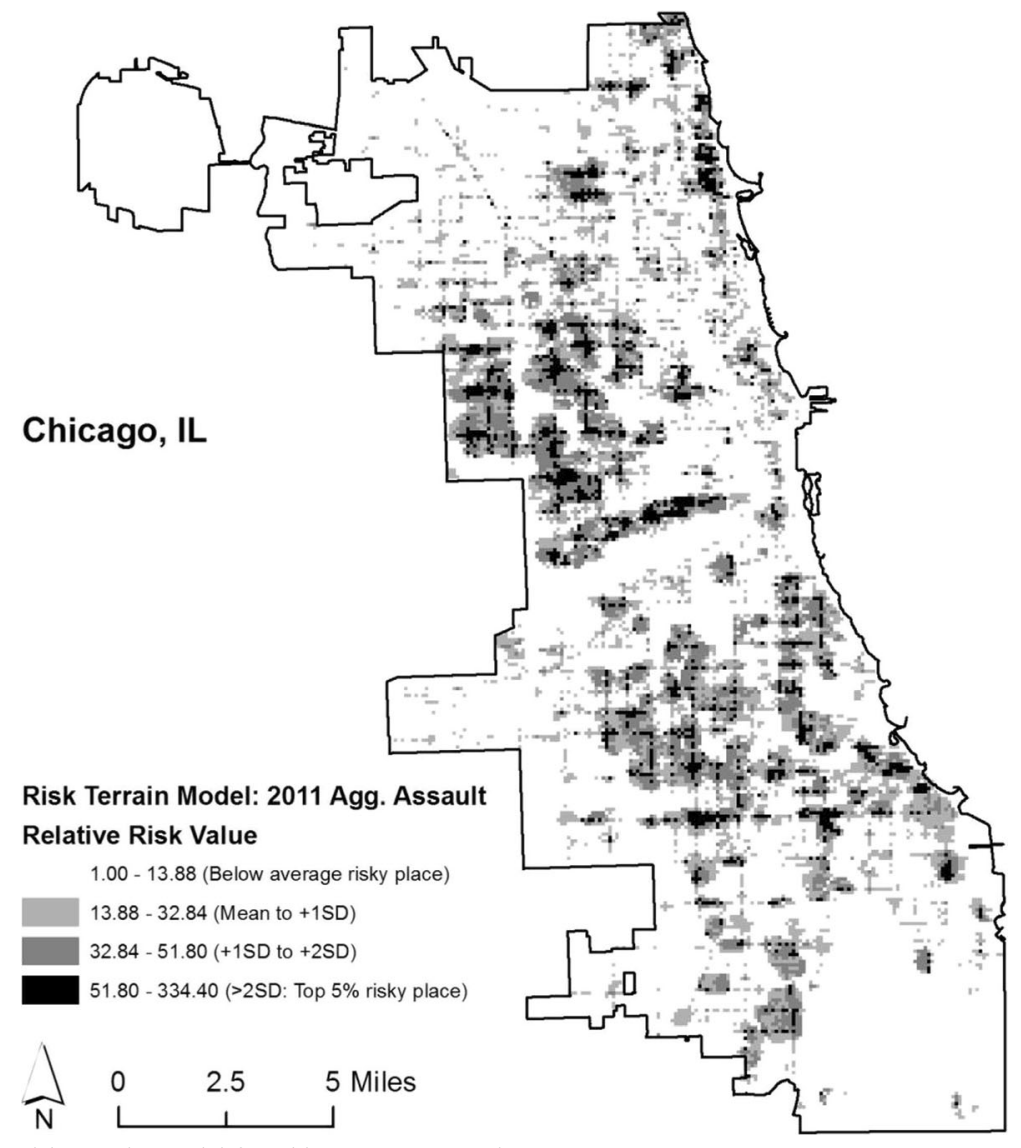

Fig. 1 Risk Terrain Model for Chicago 2011 Assaults

risk values are 13.88 and 18.96 , respectively. So, a cell (i.e., a place approximately the size of a street block) with a risk value above the mean ${ }^{7}$ has an expected aggravated assault count that is at least $29 \%$ greater than that of cells with a risk value of 1 $\left(1.02^{\wedge} 12.8=1.29\right)$. Places with risk values equal to or greater than one standard deviation above the mean (31.84) have aggravated assault counts at least $88 \%$ greater than that of cells with risk values of $1\left(1.02^{\wedge} 31.84=1.88\right)$, while places with risk values two standard deviations above the mean (i.e. the top $5 \%$ of high-risk cells) have counts nearly three times as high as cells with risk values of $1\left(1.02^{\wedge} 50.80=2.73\right)$. These probabilities are statistically significant at $p<0.001$ and empirically support Proposition 2. Higher risk (i.e., spatially vulnerable) places have an exceptionally strong likelihood of experiencing future crime incidents.

To summarize, the risk terrain map in Fig. 1 articulates environmental contexts of places that are most likely to attract or enable aggravated assaults as a function of the combined influences of criminogenic features within Chicago. These results suggest that the risk terrain map produced to articulate the environmental backcloth for

\footnotetext{
${ }_{7}$ The IRR compares to a baseline of zero, in RTM, risk scores have a baseline of 1 . So, we subtracted 1 from the mean prior to calculating the interpretation statistics.
} 
Table 2 Negative binomial results for risk values on 2012 aggravated assaults

\begin{tabular}{llllll}
\hline Variable & IRR & Std. Err. & $Z$ & $95 \%$ C.I. lower & $95 \%$ C.I. upper \\
\hline Risk value (1-334.4) & $1.01 *$ & 0.00078 & 24.99 & 1.020 & 1.021 \\
Spatial lag & $4.97 *$ & 0.190840 & 41.75 & 4.609 & 5.358 \\
\hline
\end{tabular}

$* p<0.001$

aggravated assaults in Chicago was statistically valid for forecasting purposes. The empirical predictive validity of the risk terrain model supports Proposition 2 because places that appear to be the most vulnerable on the map are also places where future aggravated assaults occurred most often (beyond random chance).

\section{Proposition 3: Spatial Intelligence and the Spatial-Temporal Context for Crime}

Having considered the importance of spatial influence and the concentration of these effects in risk terrain maps, we have a basis upon which to identify spatial vulnerability and forecast crime emergence based on this vulnerability. However, as we discussed earlier, crime does not always occur at the most vulnerable places. Exceptions can be due to a number of factors. For example, places may be high risk, but motivated offenders may not be present simultaneous to suitable victims/targets. Or, steps may have been taken to reduce crime, hence reducing exposure. If we consider that the expansion of crime prevention activities could lead to the eradication of risky places, we would want to develop a strategy for modeling these and adding them to crime forecasts. This relates to Proposition 3: the overall effect of risky places on crime is a function of vulnerability and exposure throughout the landscape.

Crime hotspot maps offer an accounting of where crime has occurred and can provide information on patterning and the clustering nature of these events (i.e., what we have conceptualized, in part, as exposure). As we explained earlier, crime tends to occur close to where other crime has happened, particularly in the short term. So near repeat analysis can be used to assess heightened risk at places near to prior crime incidents, that is, exposure caused by recent past crime events. Presumably, more precise place-based forecasts of crime occurrence could be made if vulnerable places were assessed within the context of exposures to recent past crime events at or near the same location. That is, recent crime incidents heighten the risk of new crimes to occur at vulnerable places, defined by a risk terrain map.

The near repeat calculator (Ratcliffe 2009) was used to determine whether the near repeat phenomenon existed for aggravated assaults in the study area during 2012. Based on the recommendations by Ratcliffe, the spatial bandwidth used was $426 \mathrm{ft}$ (one average Chicago block); four spatial bands were assigned. The temporal bandwidths used were 7 days and eight temporal bands. Both repeat victimization and near repeats were present for aggravated assaults in Chicago in 2012. The chance of an assault location (i.e. incident address) experiencing an additional assault within 7 days was $279 \%$ grater than would be expected if no significant near repeat pattern was evident. Additionally, areas within $426 \mathrm{ft}$ (approximately one block) of an assault location stood a $40 \%$ greater chance of experiencing an additional assault within 7 days of the 
instigator event. To summarize, near repeat aggravated assaults were most likely to occur within one block and 1 week of an instigator event.

Given this finding of a near repeat phenomenon, the "Other Functions" tool in the near repeat calculator was used to determine which incidents in a near repeat pair were the instigator and near repeat incidents. Instigator and near repeat incidents were noted accordingly in the attribute table of the point shapefile of all 2012 aggravated assaults in Chicago. Then buffers with a radius of $426 \mathrm{ft}$ were drawn around each aggravated assault incident point feature to connote the expected area for near repeat incidents to occur within 7 days. Average risk (i.e., average vulnerability) for each buffer area was calculated based on the average risk value of cells from the risk terrain map that intersected each buffer. The average risk value for all buffer areas was $32.56(n=$ 7883; standard deviation=19.76). The average risk value for buffer areas of noninstigator aggravated assault incidents was 32.04 ( $n=7173$; standard deviation= 19.72). The average risk value for buffer areas of instigator aggravated assault incidents was $38.82(n=600$; standard deviation=19.26). These differences in means between non-instigator and instigator incidents were significant at $p<0.001$, according to results from an independent samples $t$-test.

Furthermore, the proportion of high-risk cells is greater for buffer areas of instigator incidents than for non-instigator incidents; proportions are calculated as the number of cells with risk values greater than the 13.88 average divided by the total number of cells that intersect the $426 \mathrm{ft}$ buffer area. The average proportion of risky cells within $426 \mathrm{ft}$ of all aggravated assault incidents is 0.684 . That is, about $68 \%$ of places within a $426-\mathrm{ft}$ buffer of all aggravated assault incidents are influenced by at least above-average vulnerability for crime. The average proportion of risky cells within $426 \mathrm{ft}$ of noninstigator events is 0.675 . The average proportion of risky cells within $426 \mathrm{ft}$ of instigator events is 0.789 . These differences between non-instigator and instigator events are significant at $p<0.001$, according to results from an independent samples $t$-test. They are also practically meaningful in that aggravated assault incidents that become instigators for near repeats occur at places with above average proportions of nearby high-risk places. Alternatively, aggravated assault incidents that ultimately do not attract near repeats occur at places with below average proportions of nearby highrisk places. This result further supports Proposition 3.

To further explore the relationship between spatial risk and Near Repeat crime occurrence, we conducted a logistic regression model with the individual assault incidents as units of analysis. The dependent variable was a binary measure of whether the incident was an instigator event (1) or not (0). The independent variable was the average risk value of the cells falling within the incident's aforementioned buffer area. The Average Cell Risk was statistically significant $(p<0.001)$ with an odds ratio of 1.01. This suggests that with each 1-unit increase in Average Cell Risk, the odds of the incident generating additional near repeat assaults increases by $1 \%$. As previously mentioned, the average risk for all buffers was 32.56 with a standard deviation of 19.76 . Based upon the odds ratio, an aggravated assault within a buffer greater than 1 standard deviation above the mean has $22 \%$ higher odds of generating near repeat incidents than an assault within a buffer with a mean level of risk $\left(1.01^{\wedge}[52.32-32.56]=1.22\right)$ (Table 3).

The cumulative results of the t-tests and logistic regression models demonstrate that aggravated assault incidents become instigators for near repeats when they occur at 
Table 3 Logistic regression results for risk values on likelihood of incident being an instigator event

\begin{tabular}{llllll}
\hline Variable & Odds ratio & Std. Err. & Z & $95 \%$ C.I. lower & 95 \% C.I. upper \\
\hline Average risk value & $1.01 *$ & 0.00187 & 8.03 & 1.011 & 1.019 \\
\hline
\end{tabular}

$* p<0.001$

places surrounded by higher levels of risk. These findings suggest that the overall effect of risky places on crime is a function of vulnerability and exposure throughout the landscape, and lends strong support to Proposition 3.

\section{Summary and Conclusions}

Our study offers a way of improving on the spatial study of crime through the application of a vulnerability-exposure framework that considers how risky places are formed and sustained. The risk that comes from increased vulnerability tied to features in the environment, and the exposure that derives from crime incidents, concentrates at micro places and influences the new crime patterns that occur throughout an area. The stochasticity or fluctuations in criminal behavior may be the seeds from which new problem areas nucleate and grow. But, if places are not ideally suited for crime events and near repeat incidents, then they may never fully mature to be labeled "hotspots". The vulnerability-exposure framework helps to articulate such probabilities.

So, for aggravated assault in Chicago, we find that the most important predictors of occurrence are locations in which there are problem buildings. Next in importance is gang hot spots followed by the nearby presence of foreclosures. While significant, the locations that we normally associate with assaults, as reported in the previous literature, represented by bars, liquor stores, and schools are much less likely to be associated with assaults within the Chicago context. In addition, the measures that we used to represent social disorder variables, including calls to 311 numbers, have much less effect on these outcomes.

Moving to an assessment of the combined effects of these risk factors, we demonstrate that they are concentrated in identifiable areas of Chicago where vulnerability to assault is much greater than elsewhere. This calculation provides guidance to police agencies of the places to go to mitigate assaultive behavior and should encourage them to concentrate on the difficulties that problem buildings, gang hot spots and foreclosures pose to human behavior at these locations.

Finally, this research demonstrates the tight connection between exposure to crime and vulnerability. The usefulness of hot spot analysis is enhanced, as shown here, by knowledge of the vulnerable locations in which the high risk factors prevail. So, plotting assaults and then looking to see where problem buildings, drug hot spots, and foreclosures locate, will provide the police with an effective tool in identifying where assaults are likely to take place in the future.

Extending beyond the confines of this Chicago study, using the vulnerabilityexposure framework for crime analysis provides insights for a holistic response to crime problems. This approach is flexible in that it allows analysts to consider the 
characteristics of the landscape that may be emerging as problems within a jurisdiction and account for their influence and unique combinations while still taking account of what are known to be important correlates of aggravated assault. It offers a step-by-step guide for producing spatial intelligence applied to locating, anticipating, and preventing violent crime. As an applied strategy for crime control: It tells you, first, what to look for. Then, it tells you where to go to find it. Finally, it offers clues about the triggers to crime that come with previous offending and what to do about crime based on the important factors that create vulnerability in that location. The vulnerability-exposure approach provides an evidence-based method that encourages problem-oriented policing, focusing on how to change places to make them less conducive to crime (Mastrofski et al. 2010). By articulating the environmental context of crime incident locations, the framework demonstrated here can help guide analyses that identify and prioritize specific areas and features of the landscape that should be addressed by a targeted intervention. It also provides an extension of solutions for response that go beyond what has been discussed related to hotspots policing, although could include some of the strategies that have been adopted there (Koper 2014). The vulnerabilityexposure approach to crime analysis not only tells police and other stakeholders where to go based on past crime occurrences, but how to prioritize ${ }^{8}$ new crime incidents and what to do about the places to make them less vulnerable. Investigating how such things as directed patrol or saturated policing would work in concert with crime prevention and community improvement offers a way forward in addressing vulnerability and exposure (Caplan et al. 2012)

Many crime incidents at the same location create hotspots. Hotspots may expand, contract, or move over time. The evolution of hotspots depends on the actions of offenders, the interventions of police, and the changing opportunities for crime that are influenced by prevention activities. For example, we have seen that violent crime in some locations subsides because of police presence, but also because of the follow-up actions of enforcement and responses to reported crime incidents. Hotspots can appear elsewhere from where they once did, but this will most likely be the case when the host areas are most vulnerable according to the risk terrain model (i.e., spatial influence). When crime disappears from vulnerable places, should these places still be considered unsafe or suitable areas for crime to occur again? The answer based on findings of predictive validity of the risk terrain model (discussed above) is yes. Vulnerability does not change unless one or more factors that comprise the risk terrain model are

\footnotetext{
${ }^{8}$ For example: Given the expected occurrence of near repeat incidents in Chicago within a certain distance (i.e., $426 \mathrm{ft}$ ) and period of time (i.e. one week) from new crime incidents, an analytical strategy for prioritizing new crime incidents could be to evaluate each new crime incident for its propensity to become an instigator for near repeats - based upon the proportion of high-risk places within the expected near repeat bandwidth. Imagine, for instance, a crime analyst plotting a new crime incident on a risk terrain map. She then draws a buffer around it equal to the expected near repeat bandwidth to isolate all the micro-level places within the buffer. Then she identifies all the places within the buffer that are exceptionally high risk, based on the risk terrain model. Now she can advise commanders about the proportion of high-risk places within the buffer (e.g., 87 out of $237=37 \%$ ). This can inform decisions about whether to allocate resources to that crime's buffer area given the vulnerable places within it for near repeat crimes over the next 7-day period. This resource allocation decision could be made in consideration of all other recent crime incidents that have occurred in the jurisdiction so that priority can be given to those areas with the greatest propensity for new crimes to emerge in the near future. Although a risk terrain may be time-stable once it is produced (unless actions are taken to affect spatial vulnerabilities), places within the terrain can be very dynamic as each new crime incident creates exposures that subsequently alter the spatial dynamics of crime.
} 
mitigated. The spatial-temporal context for crime is merely exacerbated when vulnerable places are located near recent past crime incidents.

\section{References}

Arlot, S., \& Celisse, A. (2010). A survey of cross-validation procedures for model selection. Statistics Surveys, 4, 40-79.

Barnum, J. D., Caplan, J. M., Kennedy, L. W., \& Piza, E. L. (2013). Testing the cross jurisdictional spatial influence of attractors and generators of crime in the urban environment. Presentation at the American Society of Criminology 2013 Annual Meeting, Atlanta, Georgia.

Bernasco, W., \& Block, R. (2011). Robberies in Chicago: a block-level analysis of the influence of crime generators, crime attractors, and offender anchor points. Journal of Research in Crime and Delinquency, $48(1), 33-57$.

Block, R., \& Block, C. (1995). Space, place, and crime: Hotspot areas and hot places of liquor related crime. In J. Eck \& D. Weisburd (Eds.), Crime and place (Crime prevention studies, Vol. 4, pp. 145-184). Monsey: Criminal Justice Press.

Bowers, K. J., \& Johnson, S. D. (2005). Domestic burglary repeats and space-time clusters: the dimensions of risk. European Journal of Criminology, 2(1), 67-92.

Braga, A., \& Clarke, R. V. (2014). Explaining high-risk concentrations of crime in the city: social disorganization, crime opportunities, and important next steps. Journal of Research in Crime and Delinquency (Jan), online first.

Braga, A. A., Pierce, G. L., McDevitt, J., Bond, B. J., \& Cronin, S. (2008). The strategic prevention of gun violence among gang-involved offenders. Justice Quarterly, 25(1), 132-162.

Braga, A., Papachristos, A., \& Hureau, D. (2014). The effects of hot spots policing on crime: an updated systematic review and meta analysis. Justice Quarterly, 31(4), 633-663.

Brantingham, P., \& Brantingham, P. (1981). Environmental criminology. Beverly Hills: Sage Publications.

Brantingham, P., \& Brantingham, P. (1995). Criminality of place: crime generators and crime attractors. European Journal on Criminal Policy and Research, 3, 1-26.

Bursik, R., \& Grasmick, H. G. (1993). Neighborhoods and crime. San Francisco: Jossey Bass.

Caplan, J. M. (2011). Mapping the spatial influence of crime correlates: a comparison of operationalization schemes and implications for crime analysis and CJ practice. Cityscape, 13(3), 57-83.

Caplan, J. M., \& Kennedy, L. W. (2010). Risk terrain modeling manual: Theoretical framework and technical steps of spatial risk assessment. Newark, NJ: Rutgers Center on Public Security. [available at www. riskterrainmodeling.com].

Caplan, J. M., Kennedy, L. W., \& Miller, J. (2011). Risk terrain modeling: brokering criminological theory and GIS methods for crime forecasting. Justice Quarterly, 28(2), 360-381.

Caplan, J. M., Kennedy, L. W., \& Baughman, J. (2012). Kansas City's violent crime initiative. Crime Mapping, 4(2), 9-37.

Caplan, J., Kennedy, L. W., \& Piza, E. (2013a). Joint utility of event-dependent and environmental crime analysis techniques for violent crime forecasting. Crime and Delinquency, 59(2), 243-270.

Caplan, J. M., Kennedy, L. W., \& Piza, E. (2013b). Risk terrain modeling diagnostic user manual (Version 1.0). Newark: Rutgers Center on Public Security.

Chicago Police Department. Crime type categories: Definition \& description. Retrieved on December 19, 2014 from http://gis.chicagopolice.org/clearmap_crime_sums/crime_types.html\#N04A.

City of Chicago (2014). The city of Chicago's official site. Retrieved on September 17, 2014 from http://www. cityofchicago.org/city/en/narr/foia/CityData.html.

Drawve, G. (2014). A metric comparison of predictive hot spot techniques and RTM. Justice Quarterly, (ahead-of-print), 1-29.

Dugato, M. (2013). Assessing the validity of risk terrain modeling in a European city: preventing robberies in the city of Milan. Crime Mapping: A Journal of Research and Practice, 5(1), 63-89.

Eck, J. E., Chainey, S., Cameron, J. G., Leitner, L., \& Wilson, R. E. (2005). Mapping crime: Understanding hotspots. Washington: National Institute of Justice.

Eck, J., Clarke, R., \& Guerette, R. (2007). Ricky facilities: crime concentration in homogeneous sets of establishments and facilities. Crime Prevention Studies, 21, 225-264.

Freundschuh, S., \& Egenhofer, M. (1997). Human conceptions of spaces: implications for geographic information systems. Transactions in GIS, 2(4), 361-375. 
Golledge, R. G., \& Stimson, R. J. (1997). Spatial behavior: A geographic perspective. N.Y.: Guildford Press. Groff, E. R., \& La Vigne, N. G. (2002). Forecasting the future of predictive crime mapping. Crime Prevention Studies, 13, 29-58.

Guerette, R. T., \& Bowers, K. J. (2009). Assessing the extent of crime displacement and diffusion of benefits: a review of situational crime prevention evaluations. Criminology, 47, 1331-1368.

Harries, K. (1999). Mapping crime: Principle and practice. Washington: U.S. Department of Justice, Office of Justice Programs.

Heffner, J. (2013). Statistics of the RTMDx utility. In J. Caplan, L. W. Kennedy, \& E. Piza (Eds.), Risk Terrain Modeling Diagnostics (RTMDx) utility user manual (Version 1) (pp. 26-34). Newark: Rutgers Center on Public Security.

Hunter, R., \& Jeffery, C. (1997). Preventing convenience store robbery through environmental design. In R. Clarke (Ed.), Situational crime prevention, successful case studies, second edition. Monsey: Criminal Justice Press.

Irvin-Erickson, Y. (2015). Identifying risky places for crime: An analysis of the criminogenic spatiotemporal influences of landscape features on street robberies. Washington: Department of Justice.

Kennedy, L. W., \& Caplan, J. M. (2013). A theory of risky places. Research brief. Newark: Rutgers Center on Public Security.

Kennedy, L. W., \& Van Brunschot, E. (2009). The risk in crime. Lantham: Rowman and Littlefield.

Kennedy, L. W., Caplan, J. M., \& Piza, E. L. (2011). Risk clusters, hotspots, and spatial intelligence: risk terrain modeling as an algorithm for police resource allocation strategies. Journal of Quantitative Criminology, 28(2), 360-381.

Koper, C. (2014). Assessing the practice of hot spots policing: survey results from a National Convenience Sample of Local Police Agencies Journal of Contemporary Criminal Justice1043986214525079, first published on March 12, 2014.

Lawson, A., Biggeri, A., Böhning, D., Lesaffre, E., Viel, J. F., \& Bertollini, R. (1999). Disease mapping and risk assessment for public health. Wiley.

Lim, S. S., Vos, T., Flaxman, A. D., Danaei, G., Shibuya, K., Adair-Rohani, H., \& Davis, A. (2013). A comparative risk assessment of burden of disease and injury attributable to 67 risk factors and risk factor clusters in 21 regions, 1990-2010: a systematic analysis for the Global Burden of Disease Study 2010. The Lancet, 380(9859), 2224-2260.

Lum, C., \& Koper, C. S. (2013). Evidence-based policing in smaller agencies: challenges, prospects, and opportunities. The Police Chief 80 (April): 42-47.

Madensen, T. D., \& Eck, J. E. (2008). Spectator violence in stadiums. Washington: Office of Community Oriented Policing Services, U.S. Department of Justice.

Maguire, K. (Ed.). (2007). Sourcebook of criminal justice statistics. Retrieved from http://www.albany.edu/ sourcebook/pdf/t5452004.pdf.

Martinez, R., Jr., Rosenfeld, R., \& Mares, D. (2008). Social disorganization, drug market activity, and neighborhood violent crime. Urban Affairs Review, 43(6), 846-874.

Mastrofski, S. D., Weisburd, D., \& Braga, A. A. (2010). Rethinking policing: The policy implications of hotspots of crime. In N. A. Frost, J. D. Freilich, \& T. R. Clear (Eds.), Contemporary issues in criminal justice policy: Policy proposals from the American Society of Criminology Conference (pp. 251-264). Belmont: Wadsworth.

Mayhew, H. (1861). London labour and the London poor. NY: Dover (republished in 1968).

Moreto, W. D., Piza, E. L., \& Caplan, J. M. (2013). 'A plague on both your houses?': risks, repeats and reconsiderations of urban residential burglary. Justice Quarterly. doi:10.1080/07418825.2012.754921.

Office of National Drug Control Policy. (2000). Drug-related crime fact sheet. Washington: Office of National Drug Control Policy.

Park, R. E., McKenzie, R. D., \& Burgess, E. (1925). The city: Suggestions for the study of human nature in the urban environment. Chicago: University of Chicago Press.

Pridemore, W. A., \& Grubesic, T. (2013). Alcohol outlets and community levels of interpersonal violence: spatial density, outlet type, and seriousness of assault. Journal of Research in Crime and Delinquency, 50(1), 132-159.

Rand, M. R. (2008). Criminal victimization, 2007. Washington: U.S. Department of Justice, Bureau of Justice Statistics.

Ratcliffe, J. (2009). Near Repeat Calculator (version 1.3). Temple University, Philadelphia, PA and the National Institute of Justice, Washington, DC.

Ratcliffe, J. H., \& Rengert, G. (2008). Near repeat patterns in Philadelphia shootings. Security Journal, 21(12), 58-76. 
Rengert, G., Ratcliffe, J., \& Chakravorty, S. (2005). Policing illegal drug markets: Geographic approaches to crime reduction. Monsey: Criminal Justice Press.

Roncek, D. W., \& Faggiani, D. (1985). High schools and crime. The Sociological Quarterly, 26, 491-505.

Scott, M. S., \& Dedel, K. (2006). Assault in and around bars (2nd ed.). Washington: Office of Community Oriented Policing Services, U.S. Department of Justice.

Shaw, C., \& McKay, H. (1969). Juvenile delinquency and urban areas. Chicago: University of Chicago Press.

Sherman, L., \& Rogan, D. (1995). Deterrent effects of police raids on crack houses: a randomized controlled experiment. Justice Quarterly, 12, 755-782.

Sherman, L. W., Gartin, P. R., \& Buerger, M. E. (1989). Hotspots of predatory crime: routine activities and the criminology of place. Criminology, 27, 27-55.

Silver, N. (2012). The signal and the noise: Why so many predictions fail but some don't. N.Y.: Penguin.

Snowden, A. J., \& Pridemore, W. A. (2013). Alcohol and violence in a nonmetropolitan college town: alcohol outlet density, outlet type and assault. Journal of Drug Issues, 43(3), 357-373.

Stucky, T. D., \& Ottensmann, J. R. (2009). Land use and violent crime. Criminology, 47(4), 1223-1264.

Taylor, R. B. (1988). Human territorial functioning. New York: University of Cambridge Press.

Taylor, R. B., \& Harrell, A. V. (1996). Physical environment and crime. Washington: National Institute of Justice.

Tobler, W. (1970). A computer movie simulating urban growth in the Detroit region. Economic Geography, 46(2), 234-240.

Tomlin, C. D. (1994). Map algebra: one perspective. Landscape and Urban Planning, 30, 3-12.

U.S. Department of Justice, National Gang Intelligence Center. (2009). National gang threat assessment. Washington: U.S. Government Printing Office.

Weisburd, D., Wyckoff, L., Ready, J., Eck, J., Hinkle, J., \& Gajewski, F. (2006). Does crime just move around the corner? A controlled study of spatial displacement and diffusion of crime control benefits. Criminology, 44, 549-592.

Weisburd, D., Morris, N., \& Groff, E. (2009). Hot spots of juvenile crime: a longitudinal study of arrest incidents at street segments in Seattle, Washington. Journal of Quantitative Criminology, 25, 443-467.

Weisburd, D., Groff, E., \& Yang, S. (2012). The criminology of place: Street segments and our understanding of the crime problem. Oxford: Oxford University Press.

Yerxa, M. (2013). Evaluating the temporal parameters of risk terrain modeling with residential burglary. Crime Mapping, 5(1), 7-38. 